\title{
Applicability of the whole-house air conditioning system in cold climate district
}

\author{
Sihwan $\mathrm{LEE}^{1, *}$, Takuya $\mathrm{KISHI}^{1}$, and Yoshiharu ASANO ${ }^{1}$ \\ ${ }^{1}$ Shinshu University, Department of Architecture, 4-17-1 Wakasato Nagano, Japan
}

\begin{abstract}
The number of sudden deaths while bathing related to heat shock in Japan is approximately 17,000 people for a year. This number is over $30 \%$ of elderly people dying in the residential buildings. To solve this problem, it is effective to introduce a whole-house air conditioning system in the residential buildings. The purpose of this study is to evaluate the applicability of the whole-house air conditioning system in cold climate district in Japan. To achieve this goal, this study is evaluated the thermal environment by using the wholehouse air conditioning system and compared with individual air conditioning system. The results show that the maximum room temperature difference is measured approximately $6.8^{\circ} \mathrm{C}$. As the reverse simulation in the study, this temperature difference can be decreased to approximately $4{ }^{\circ} \mathrm{C}$ by adjusting the supply airflow rate. When the individual air conditioning is used, the room temperature difference is $7.5^{\circ} \mathrm{C}$. It means that using the whole-house air conditioning system decreases the room temperature difference and reduces heat shock risk. It is also possible to raise the surface temperature of the wall by 20 to $30 \%$ than in case of using individual air conditioning, thus it is effective in preventing dew condensation on the wall surface.
\end{abstract}

\section{Introduction}

A local air-conditioning for occupied room is mainly used in Japan, thus individual cooling and heating units placed in each room of the house such as a stove, an air conditioner (hereinafter abbreviated as AC), and a kotatsu etc. By using these individual cooling and heating units, health risks have been occured as a problem such as mold and tick caused by dew condensation or heat shock caused by temperature irregulation between rooms. The number of deaths due to heat shock is estimated to be 17,000 people per year in Japan [1], accounting for about $30 \%$ of the 59,416 deaths from annual accidents [2].

To solve this problem, the central cooling and heating system has been received attention to prevent the heat shock in residential buildings. The central cooling and heating is limited in Japan, because the space of mechanical equipment room and individual needs to adjust the thermal comfort have been increased. So, the whole-house air conditioning system is proposed and installed to residential buildings by several HVAC makers in Japan. The system has merit in using residential buildings to decrease the space for mechanical equipment room. However, it is few cases that it is introduced in cold areas and evaluated by actual measurement. The purpose of this study is to evaluate the indoor thermal environment by the whole-house air conditioning system in cold climate district in Japan. To achieve this goal, we evaluate the indoor thermal environment by actual measurement, and examine the improvement using CFD reverse analysis. Moreover, the indoor thermal environment compares with individual air conditioning system.

\section{Whole-house air conditioning system}

Figure 1 shows the schematics of the whole-house AC system. This system is composed of three parts such as air conditioner, total heat exchanger, and fans for air supply to each room. The split-type air conditioner put in the AC room on the 2 nd floor as a heat source. The fresh outdoor air is also inflow to the AC room after heat exchange with the return air from the room by the total heat exchanger. After the air-conditioned air and the fresh air are mixed in $\mathrm{AC}$ room, there are supplied to each room via a duct by using direct current fans. The ceiling duct is used for 2 nd floor rooms, and the underfloor plenum is used 1 st floor rooms. The supply air is returned to the AC room through the undercut of the door or the stairs.

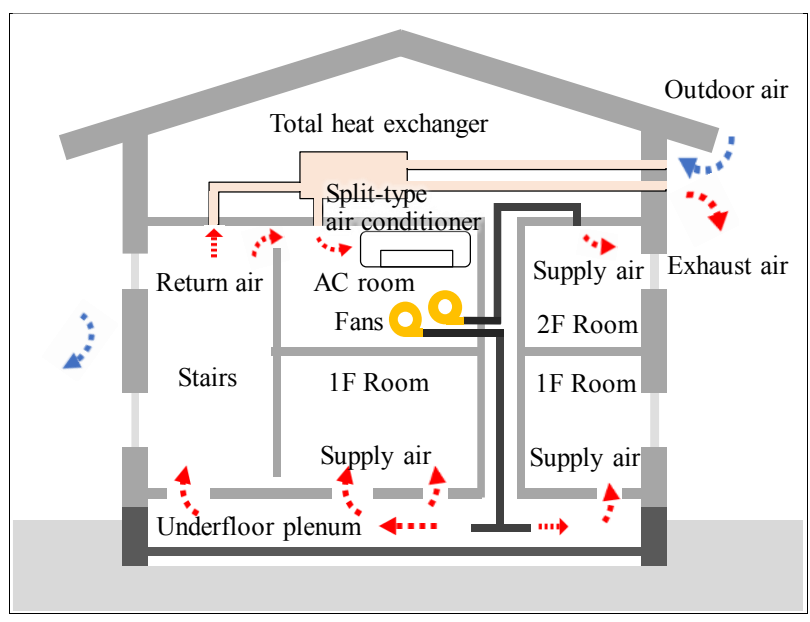

Fig. 1. Schematics of the whole-house AC system.

\footnotetext{
* Corresponding author: shany@shinshu-u.ac.jp
} 


\section{Methods}

\subsection{Actual measurement}

Figure 2 shows the target building located in Nagano, Japan. An average U-value of building envelop is calculated $0.55 \mathrm{~W} /\left(\mathrm{m}^{2} \cdot \mathrm{K}\right)$, and an specific leakage area by the net floor area is measured $0.30 \mathrm{~cm}^{2} / \mathrm{m}^{2}$ when the pressure difference between indoor and outdoor is $10 \mathrm{~Pa}$ [3]. Figure 3 shows the supply air inlet locations, and the specifications for the whole-house AC system is shown in Table 1. The undercut of each door is $15 \mathrm{~mm}$ or more and promotes air circulation. Table 2 shows the measurement conditions. The air temperature, humidity of each room and the electric current of the AC system are measured to evaluate the indoor thermal environment and the energy performance. The airflow rate for $1 \mathrm{st}$ floor is designed 800 $\mathrm{m}^{3} / \mathrm{h}$ and the 2 nd floor is designed $300 \mathrm{~m}^{3} / \mathrm{h}$. The set-point temperature of the $\mathrm{AC}$ is $22{ }^{\circ} \mathrm{C}$. Because this system assumes continuous heating for 24 hours, the measurement is performed for 10 days and a stable operated day is taken for analysis.

\subsection{Optimization of airflow rate for each room}

To enhance the non-uniform temperature distribution, airflow rates of supply inlets are optimized by using reverse CFD simulation. The design target value is set up as the room temperature. The changing parameter is set up as airflow rate of supply inlets. Then, the changing parameter is changed little by little until to satisfy a convergence between the design target value and calculated value from the forward CFD simulation results. The convergence of the design target value for iterative calculation is performed as $\pm 0.5^{\circ} \mathrm{C}$. The design target value is set up $22{ }^{\circ} \mathrm{C}$ as an average room temperature of for each room. In this simulation, the non air conditioned room is except for calculation such as a ceiling, an underfloor plenum, a toilet, and a bathroom.

Table 3 shows the boundary conditions for forward CFD simulation. Assuming 27. Jan. 0:00 as the time, the calculation model is performed. The outdoor temperature is set to $-10.3{ }^{\circ} \mathrm{C}$, which is the same as the measured value. The underground temperature is set to $15^{\circ} \mathrm{C}$, and the supply air temperature is set to $32{ }^{\circ} \mathrm{C}$ for the 1 st floor, $39{ }^{\circ} \mathrm{C}$ for the 2 nd floor. The supply air temperature for 1 nd floor is less than the value for the 2 nd floor, because it is blown out after being heat exchanged in the underfloor plenum. Heat transfer rate is referred to literature [4].

\subsection{Comparison with individual $A C$}

To compare between a case using the whole-house AC and a case using the individual $\mathrm{AC}$, the CFD simulation model is performed. In case using the whole-house AC, indoor thermal environment and dew condensation on the wall is calculated using the optimal airflow rate from chapter 3.2. In case using the individual $\mathrm{AC}$, the air conditioner is installed in 4 rooms (living room, bedroom, north-side nursery, and south-side nursery) and the airflow rate is set to $600 \mathrm{~m}^{3} / \mathrm{h}$ for each room. The set-point temperature is set to $22{ }^{\circ} \mathrm{C}$ respectively.

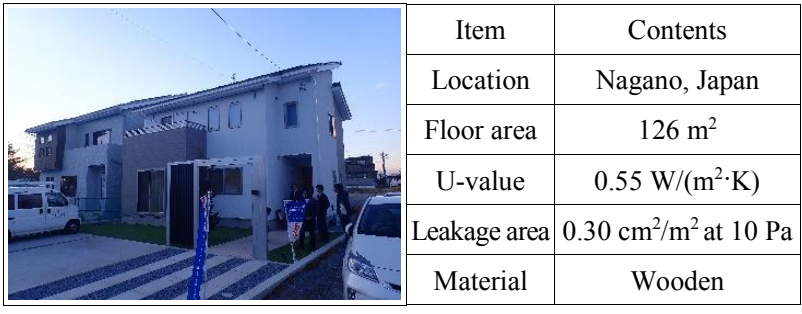

Fig. 2. Target building for actual measurement.

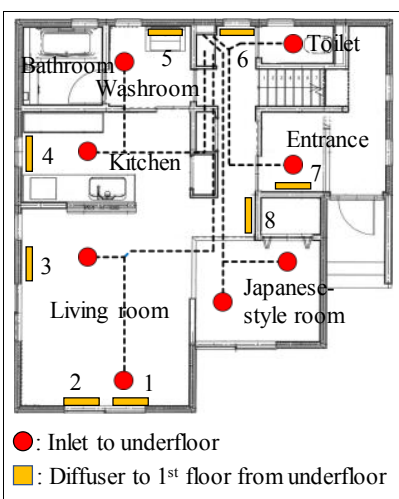

(a) 1 st floor

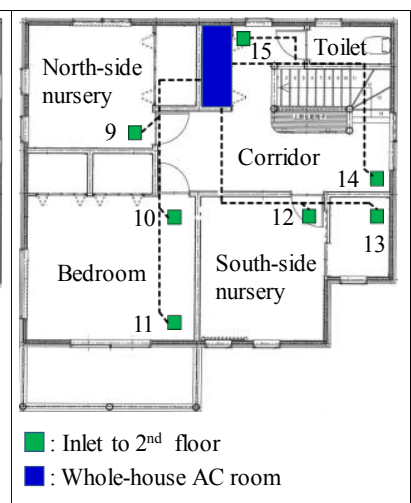

(b) 2nd floor
Fig. 3. Supply air inlet locations.

Table 1. Specifications for the whole-house AC system.

\begin{tabular}{|c|c|c|}
\hline Item & Airflow rate & Electric power consumption \\
\hline $\mathrm{AC}$ & $1,344 \mathrm{~m}^{3} / \mathrm{h}$ & $1,740 \mathrm{~W}$ (Capacity: $5,600 \mathrm{~W})$ \\
\hline \multirow{2}{*}{ Fans } & $200 \mathrm{~m}^{3} / \mathrm{h}($ High) & $4.8 \mathrm{~W}$ (High) \\
& $100 \mathrm{~m}^{3} / \mathrm{h}($ Low) & $3.0 \mathrm{~W}$ (Low) \\
\hline $\begin{array}{c}\text { Total heat } \\
\text { exchanger }\end{array}$ & $169 \mathrm{~m}^{3} / \mathrm{h}($ High) & $93 \mathrm{~W}$ (High) \\
$71 \mathrm{~m}^{3} / \mathrm{h}($ Low $)$ & $54 \mathrm{~W}$ (Low ) \\
\hline
\end{tabular}

Table 2. Measurement conditions

\begin{tabular}{|c|c|}
\hline Item & Contents \\
\hline Airflow rate & $\begin{array}{l}1 \mathrm{~F}: 800 \mathrm{~m}^{3} / \mathrm{h}(4 \text { fans }) \text { via underfloor plenum } \\
2 \mathrm{~F}: 300 \mathrm{~m}^{3} / \mathrm{h}(3 \text { fans }) \text { via ceiling duct }\end{array}$ \\
\hline Setpoint temperature & $22^{\circ} \mathrm{C}$ \\
\hline Analysis period & 27.Jan.2018, 0:00 24:00 (24 hours) \\
\hline
\end{tabular}

Table 3. Boundary conditions for forward CFD simulation.

\begin{tabular}{|c|c|}
\hline Item & Contents \\
\hline Time dependence & Steady state calculation \\
\hline Domain & $8.6(\mathrm{x}) \times 9.1(\mathrm{y}) \times 6.8(\mathrm{z}) \mathrm{m}$ \\
\hline Meshes & 742,152 ea \\
\hline Turbulent model & High-Reynolds number k-epsilon model \\
\hline Algorithm & SIMPLEC \\
\hline Radiation calculation & View factor calculation \\
\hline Buoyancy & Boussinesq approximation \\
\hline Temperature condition & Outdoor: $-10.3^{\circ} \mathrm{C}$, Underground: $15^{\circ} \mathrm{C}$ \\
\hline Heat transfer coefficient & $\mathrm{h}_{\mathrm{o}}=23.0 \mathrm{~W} /\left(\mathrm{m}^{2} \cdot \mathrm{K}\right), \mathrm{h}_{\mathrm{i}}=9.0 \mathrm{~W} /\left(\mathrm{m}^{2} \cdot \mathrm{K}\right)$ \\
\hline Inflow & $1 \mathrm{~F}: 800 \mathrm{~m}^{3} / \mathrm{h}, 32^{\circ} \mathrm{C}, 2 \mathrm{~F}: 300 \mathrm{~m}^{3} / \mathrm{h}, 39^{\circ} \mathrm{C}$ \\
\hline Outflow & $1,100 \mathrm{~m}^{3} / \mathrm{h}$ to AC room \\
\hline Simulation time & $27 . \mathrm{Jan}^{\circ} 2018,0: 00$ \\
\hline
\end{tabular}




\section{Results}

\subsection{Result of the actual measurement}

Figure 4(a) shows the measurement result of each room temperature and Fig. 4(b) shows the room temperature for 24 hours as a box and whisker plot. The temperature of the 2 nd floor toilet is the lowest, and the temperature unevenness from the living room is about $6.8^{\circ} \mathrm{C}$ at the maximum. In the south-facing bedroom, living, and South nursery where the influence of solar radiation is large, the daily difference increases. Figure 4(c) shows the vertical temperature at the stairs. The vertical temperature difference was measured $1{ }^{\circ} \mathrm{C}$ to $1.5^{\circ} \mathrm{C}$.

\subsection{Results of optimization for airflow rate}

Figure 5 shows the CFD simulation results of indoor temperature distribution when the whole-house AC system is operated by using designed airflow rate. Figure 6 shows the comparison of measured value and CFD simulation result. The CFD model was consistent with the actual measurement and it is possible to reproduce the indoor thermal environment with the actual findings.

Table 5 shows the optimized airflow rate for each diffuser and inlet. The result shows the airflow rate in all the living rooms on the 2 nd floor is requested to raise. Especially the north nursery and the bedroom are about twice the designed airflow rate. The airflow rate on the $1 \mathrm{st}$ floor is requested to reduce $41 \%$ at washroom and $42 \%$ at the entrance than designed airflow rate, respectively.

Figure 7 shows the indoor temperature distribution by using optimum airflow rate. North-side nursery, south-side nursery, bedroom, and entrance to be air conditioned improved to almost $22{ }^{\circ} \mathrm{C}$, and the room temperature unevenness is suppressed to about $3{ }^{\circ} \mathrm{C}$ at the maximum. The temperature of toilet and bathroom is not satisfied to $22{ }^{\circ} \mathrm{C}$, because it does not belong to the air conditioning route. However, the temperature of the toilet is increased to $1.2 \sim 1.3{ }^{\circ} \mathrm{C}$, because the adjacent room temperature is increased.

\subsection{Results of comparison with individual AC and whole-house AC}

Figure 8 shows the indoor temperature distribution in the case of the individual AC. The temperature in the non air conditioned room was lowered remarkably such as entrance, toilet. Figure 9(a) shows the comparison the case using whole-house AC and the case using individual AC. A normal distribution as shown in Fig. 9(b) is made from all meshes in each room. Although the temperature of every room was made uniform in case of the whole-house AC, it was made non-uniform in case of the individual AC.

Figures 10 and 11 show the relative humidity of wall in the case of the whole-house $\mathrm{AC}$ and in the case of the individual AC. The relative humidity shows the case where $8.65 \mathrm{~g} / \mathrm{m}^{3}\left(20^{\circ} \mathrm{C}\right.$, $50 \% \mathrm{RH}$ ) is contained in the air at the same temperature as the wall temperature. The dew condensation is occurred in non air conditioned room in the case of the individual $\mathrm{AC}$, but it was not occurred in case of the whole-house AC.

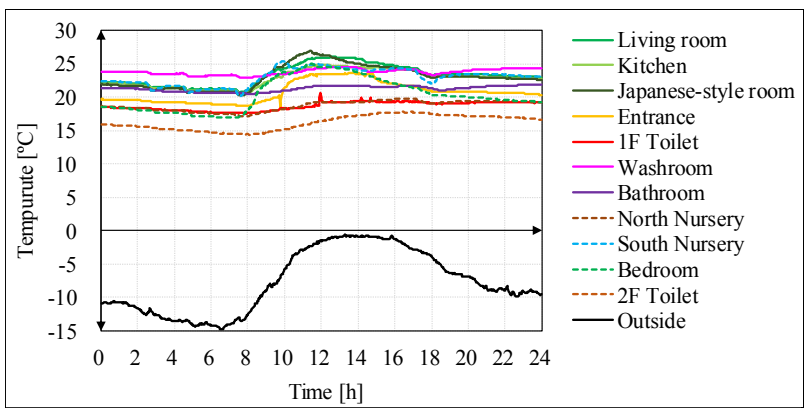

(a) Room temperature

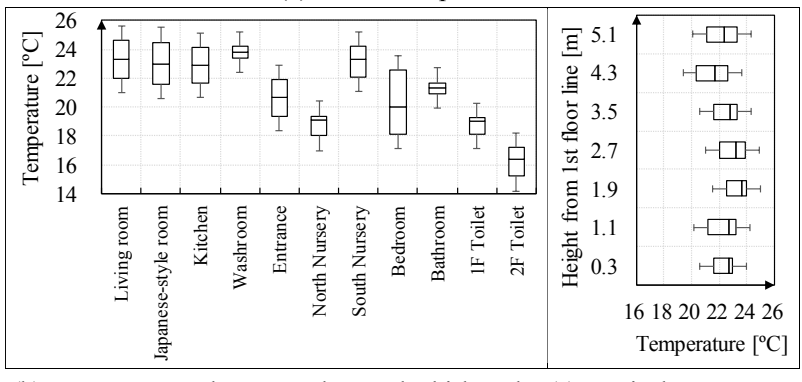

(b) Tempereature shown as a box and whisker plot (c) Vertical temperature

Fig. 4. Measurement result of room and vertical temperature.

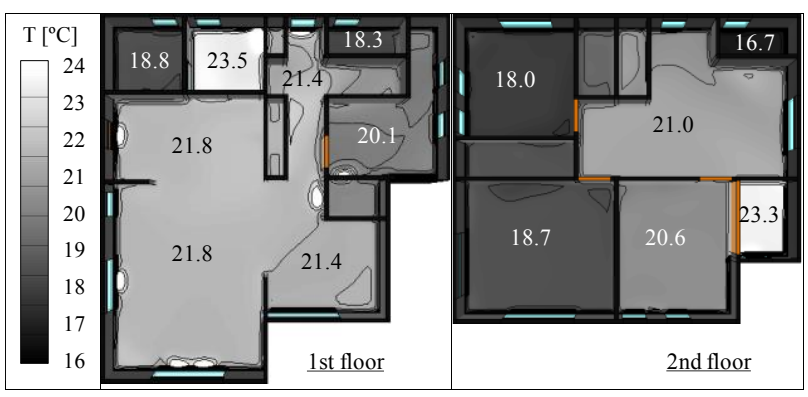

Fig. 5. CFD results by using designed airflow rate (validation).

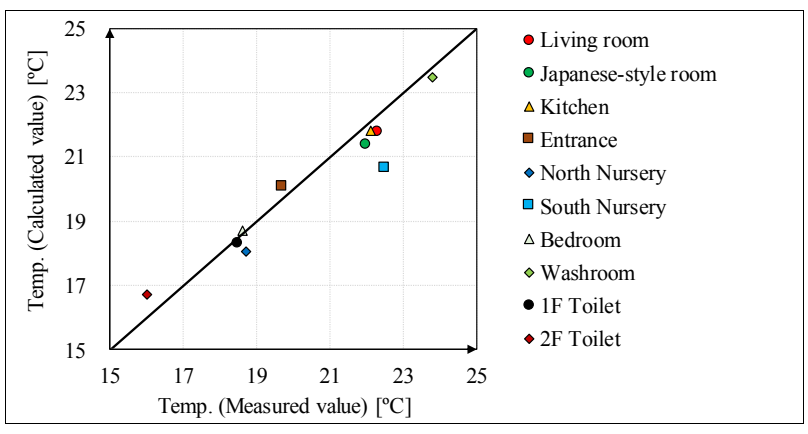

Fig. 6. Validation of CFD simulation.

Table 5. Calculated optimal airflow rate by reverse simulation.

\begin{tabular}{|c|c|c|c|c|c|}
\hline $\begin{array}{c}\text { 1st floor } \\
\text { diffuser } \\
\text { No. }\end{array}$ & $\begin{array}{c}\text { Designed } \\
\text { airflow rate } \\
{\left[\mathrm{m}^{3} / \mathrm{h}\right]}\end{array}$ & $\begin{array}{c}\text { Claculated } \\
\text { airflow rate } \\
{\left[\mathrm{m}^{3} / \mathrm{h}\right]}\end{array}$ & $\begin{array}{c}\text { 2nd floor } \\
\text { inlet No. }\end{array}$ & $\begin{array}{c}\text { Designed } \\
\text { airflow rate } \\
{\left[\mathrm{m}^{3} / \mathrm{h}\right]}\end{array}$ & $\begin{array}{c}\text { Claculated } \\
\text { airflow rate } \\
{\left[\mathrm{m}^{3} / \mathrm{h}\right]}\end{array}$ \\
\hline 1 & 100.0 & 102.2 & 9 & 40.0 & 83.5 \\
\hline 2 & 100.0 & 90.0 & 10 & 30.0 & 59.1 \\
\hline 3 & 100.0 & 92.2 & 11 & 30.0 & 63.2 \\
\hline 4 & 100.0 & 95.6 & 12 & 50.0 & 54.2 \\
\hline 5 & 100.0 & 59.1 & 13 & 50.0 & 39.1 \\
\hline 6 & 100.0 & 98.4 & 14 & 50.0 & 49.0 \\
\hline 7 & 100.0 & 142.3 & 15 & 50.0 & 58.8 \\
\hline 8 & 100.0 & 102.5 & & & \\
\end{tabular}




\section{Discussion}

The target building has high-performance low emissivity glass windows with a heat transmission coefficient of 2.14 $\mathrm{W} /\left(\mathrm{m}^{2} \cdot \mathrm{K}\right)$. The dew condensation is occurred in case of individual AC even in such highly insulated houses, when the outdoor temperature is $-10^{\circ} \mathrm{C}$. However, in case of the whole-house AC system is prevented the dew condensation.

A heat shock is caused by changes in blood pressure due to temperature difference. Saito M., et al. [5] mentioned that the blood pressure rises with a probability of $80 \%$ under the condition of temperature difference over $5{ }^{\circ} \mathrm{C}$. Although the temperature difference was $7.5^{\circ} \mathrm{C}$ in case of the individual AC, it was kept within $4{ }^{\circ} \mathrm{C}$ in case of the whole-house AC. Therefore, the risk of blood pressure rise can be reduced by using the whole-house AC system. Moreover, the whole-house AC system is also effective for preventing dew condensation in cold district.

\section{Conclusions}

This paper had evaluated the indoor environment by the whole-house air conditioning introduced to cold district house by actual measurement and CFD simulation. The following conclusions can be drawn from the results of the study:

(1) The room temperature difference is measured $6.8^{\circ} \mathrm{C}$ maximum by using the whole-house $\mathrm{AC}$ system. It can be reduced to approximately $4{ }^{\circ} \mathrm{C}$ (In case of the individual AC: $7.5^{\circ} \mathrm{C}$ ) by adjusting the airflow rate for each room.

(2) Adjusting the airflow rate balance by reverse CFD simulation makes it possible to reduce the room temperature difference. However, it is not expected that improvement of the indoor thermal environment at non air conditioned room.

(3) The dew condensation is occurred at the window in non air conditioned room in case of the individual $\mathrm{AC}\left(20^{\circ} \mathrm{C}\right.$, $50 \% \mathrm{RH})$, but it was not occurred in the case of the wholehouse AC. Therefore, the whole-house AC system is also effective for preventing dew condensation in cold district.

\section{References}

1. Regional independent administrative agency Tokyo Metropolitan Health and long-term medical centre: Temperature control and health in residence in winter, pp.77-82 (2013).

2. Ministry of Health and Social Affairs Statistics Information Division Demographics and Health and Social Statistics Division: General overview of population dynamics statistics (confirmed number) in Heisei 23, Ministry of Health, Labor and Welfare (2011).

3. ISO9972: Thermal performance of buildings - Determination of air permeability of buildings - Fan pressurization method (2015).

4. Syunroku T., et al:: Architectural Environmental Engineering, revised 3rd ed., Inouesyoin p.195 (2012).

5. Saito M., et. al.: Blood pressure change of elderly with room air tempreture change during the bathing in winter of Sapporo and Fukui, Architectural Institute of Japan, Journal of Technology and Design, Vol.17, No.36, pp.569-572 (2011).

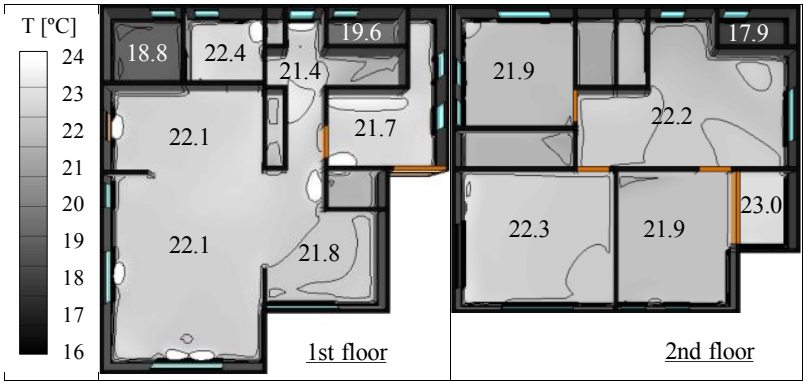

Fig. 7. CFD results by using optimum airflow rate.

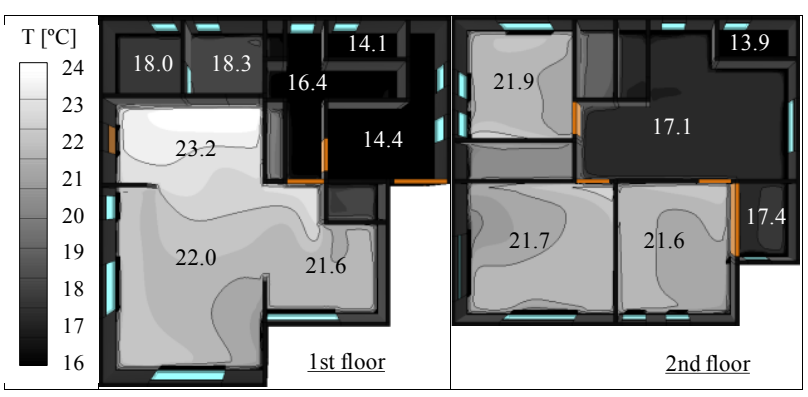

Fig. 8. CFD results in case of the individual AC.

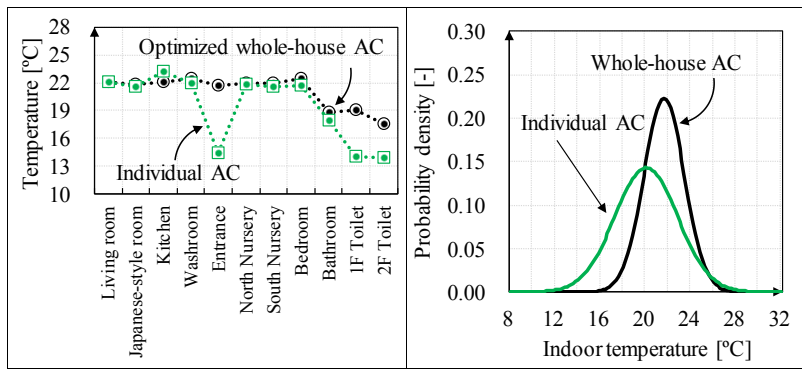

(a) Temperature of each room

(b) Normal distribution

Fig. 9. Comparison with the case using whole-house AC and the case using individual AC.

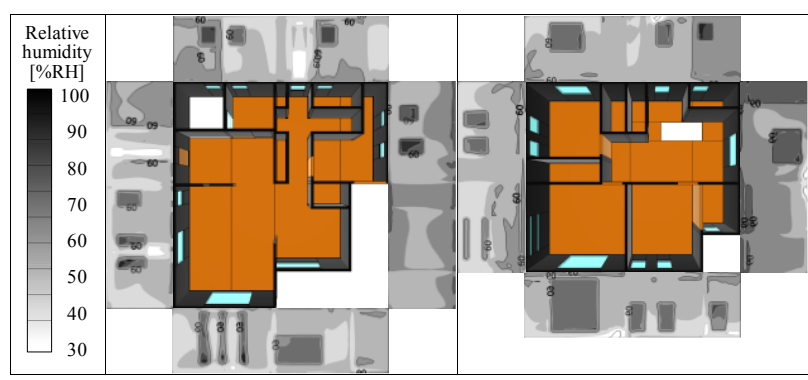

(a) 1 st floor

(b) 2nd floor

Fig. 10. Relative humidity on the wall by the whole-house AC.

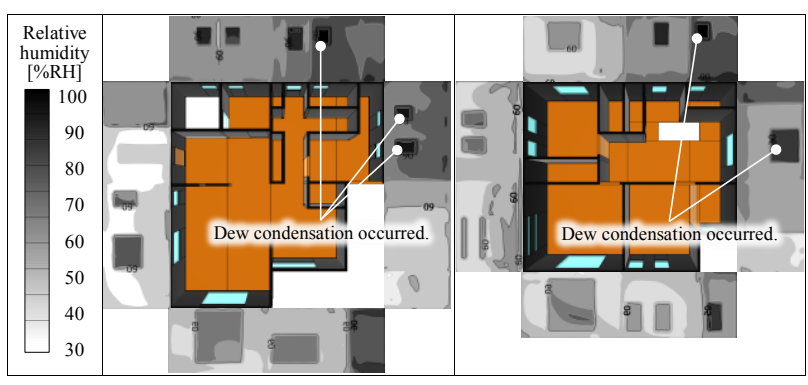

(a) 1 st floor

(b) 2nd floor

Fig. 11. Relative humidity on the wall by the individual AC. 